\title{
Tropical Deep Convection Impact on Southern Winter Stationary Waves and Its Modulation by the Quasi-Biennial Oscillation ${ }^{\mathscr{O}}$
}

\author{
CRISTINA PEÑA-ORTIZ \\ Universidad Pablo de Olavide, Sevilla, Spain \\ Elisa Manzini AND Marco A. Giorgetta \\ Max Planck Institute for Meteorology, Hamburg, Germany
}

(Manuscript received 7 November 2018, in final form 26 June 2019)

\begin{abstract}
The impact of tropical deep convection on southern winter stationary waves and its modulation by the quasi-biennial oscillation (QBO) have been investigated in a long (210 year) climate model simulation and in ERA-Interim reanalysis data for the period 1979-2018. Model results reveal that tropical deep convection over the region of its climatological maximum modulates high-latitude stationary planetary waves in the southern winter hemisphere, corroborating the dominant role of tropical thermal forcing in the generation of these waves. In the tropics, deep convection enhancement leads to wavenumber-1 eddy anomalies that reinforce the climatological Rossby-Kelvin wave couplet. The Rossby wave propagates toward the extratropical southern winter hemisphere and upward through the winter stratosphere reinforcing wavenumber-1 climatological eddies. As a consequence, stronger tropical deep convection is related to greater upward wave propagation and, consequently, to a stronger Brewer-Dobson circulation and a warmer polar winter stratosphere. This linkage between tropical deep convection and the Southern Hemisphere (SH) winter polar vortex is also found in the ERA-Interim reanalysis. Furthermore, model results indicate that the enhancement of deep convection observed during the easterly phase of the QBO (E-QBO) gives rise to a similar modulation of the southern winter extratropical stratosphere, which suggests that the QBO modulation of convection plays a fundamental role in the transmission of the QBO signature to the southern stratosphere during the austral winter, revealing a new pathway for the QBO-SH polar vortex connection. ERA-Interim corroborates a QBO modulation of deep convection; however, the shorter data record does not allow us to assess its possible impact on the $\mathrm{SH}$ polar vortex.
\end{abstract}

\section{Introduction}

Stationary planetary waves play an important role in the stratospheric circulation and temperature, being a major forcing of the Brewer-Dobson circulation (Cohen et al. 2014). They propagate from the troposphere where they are generated by different orographic and thermal forcings. In the Southern Hemisphere ( $\mathrm{SH}$ ) the stationary (monthly mean) wave field is dominated by the zonal wavenumber- 1 component (herein called wave 1 ), which reaches its maximum amplitude at about $60^{\circ} \mathrm{S}$ in

\footnotetext{
Supplemental information related to this paper is available at the Journals Online website: https://doi.org/10.1175/JCLI-D-180763.s1.
}

Corresponding author: Cristina Peña-Ortiz, cpenort@upo.es the upper troposphere and stratosphere (Quintanar and Mechoso 1995a). Initially, the climatological SH stationary wave 1 had been related to the Antarctic orography and associated thermal effects (James 1988). However, Quintanar and Mechoso (1995b) used a general circulation model to show that this forcing was secondary and pointed out to a remote thermal forcing of wave activity from lower latitudes as the primary driver. Consistently, model analysis by Inatsu and Hoskins (2004) attributed the forcing of SH stationary eddies to the zonal asymmetries in tropical SSTs that would originate a Rossby wave train over the Indian Ocean, which would propagate poleward and eastward around the SH. The tropical origin of the SH stationary wave is consistent with several studies showing evidence of responses of the global atmospheric circulation to heating in tropical convection (Sardeshmukh and Hoskins 1988; Bladé and Hartmann 
1995; Jin and Hoskins 1995; Hendon and Salby 1996; Matthews and Meredith 2004). The Matsuno-Gill model (Matsuno 1966; Gill 1980) explains that zonally varying tropical heating, which could be produced by zonally asymmetric convection, gives rise to Kelvin and Rossby waves extending eastward and westward, respectively, of the region of heating. Rossby waves in turns can propagate poleward (visualized by "wavetrains") and around the globe. Nevertheless, although these aforementioned studies point to a tropical thermal forcing linked to zonally asymmetric convection, the precise origin and mechanism giving rise to the SH stationary waves is still an open question. Mean precipitation rates for the austral winter evidence a large area with a strong maximum in deep convection extending from the tropical northwestern Pacific to India (Dima et al. 2005; Russo et al. 2011). Convection over this region gives rise to a climatological stationary wave pattern in the tropical upper troposphere during southern winter, characterized by a Rossby-Kelvin wave couplet (Dima et al. 2005). Here we explore the possible linkage between deep convection over the climatological maximum and extratropical southern winter stationary waves through the poleward propagation of tropical stationary Rossby waves.

Previous studies have also found evidences of a linkage between the quasi-biennial oscillation (QBO) and deep convection. The QBO dominates the interannual variability of the equatorial zonal wind in the stratosphere (Baldwin et al. 2001; Anstey and Shepherd 2014). Gray et al. (1992) first found QBO-linked variations of deep convection, which they attributed to the contrasting east phase versus west phase vertical wind shear conditions in the upper troposphere and lower stratosphere (UTLS). On the other hand, Giorgetta et al. (1999) found in model studies that during austral winter the monsoon system was modulated by the QBO. They proposed a mechanism based on the tropical UTLS temperature anomaly initiated by the adiabatic temperature change due to the secondary circulation of the QBO. Thus, the UTLS cooling linked to the easterly QBO jet causes a lower static stability that allows deep convection to develop more vigorously. In agreement with Giorgetta et al. (1999), Collimore et al. (2003) also found QBO fluctuations of convection, which they attributed to either temperature anomalies induced by the QBO secondary circulation or vertical wind shear conditions in the UTLS induced by the QBO. More recently, Son et al. (2017) found that the MJO activity around the Maritime Continent was stronger during easterly QBO winters, explaining up to $40 \%$ of interannual variation of the boreal winter $\mathrm{MJO}$ amplitude. Son et al. (2017) suggests that this QBO-MJO link is consistent with the thermal stratification change in the upper troposphere. Giorgetta et al. (1999) related the QBO effects on deep convection with the excitation of a wave train in the tropospheric circulation in July and August, which extended the QBO signature to the midlatitudes in both hemispheres. They showed that this wave had an impact on radiative and atmospheric moisture fluxes as well as in precipitation from the equatorial regions to the midlatitudes, mainly in the Northern Hemisphere. In spite of the fact that the relation between the QBO modulation of convection and the excitation of Rossby waves have been previously assessed, the potential of this modulation to influence the wave patterns propagating through the $\mathrm{SH}$ winter stratosphere has not previously been examined in the literature.

Most earlier studies addressing the QBO influence in the extratropical stratosphere have focused on the northern winter (Baldwin et al. 2001; Calvo et al. 2007), where the QBO signature on the polar vortex is the strongest, and explain this tropical-extratropical connection through the Holton and Tan mechanism (Holton and Tan 1980). In regard to the SH, previous studies (Baldwin and Dunkerton 1998; Hitchman and Huesmann 2009) observed the strongest QBO signature on the polar vortex during the southern spring. For the southern winter stratosphere, Baldwin and Dunkerton (1998) found that the QBO signature was restricted to middle latitudes and upper levels. They suggested that planetary waves do not significantly disrupt the southern winter polar vortex in the lower and middle stratosphere due to the fact that this is much stronger than the northern one. However, Hitchman and Rogal (2010) showed that during the southern winter Rossby wave activity associated with subtropical monsoon anticyclones in the UTLS can propagate into the Southern Hemisphere stratospheric westerlies and influence the extratropical stratosphere. Therefore we will assess the impact of the QBO-deep convection linkage on southern winter extratropical Rossby waves and the QBO impact on upward propagation extratropical waves as a possible pathway for the QBO modulation of the southern winter polar vortex.

Thus, this paper addresses two related questions. Specifically, the first question we address is if the $\mathrm{SH}$ stationary waves respond to deep convection variability over the climatological maximum, regardless of the QBO or any other specific climate pattern. This examination serves to shed some light on the role of deep convection as a possible driver of this wave pattern. The second question is if the QBO may have an impact on the southern winter stratospheric polar vortex via the modulation of tropical deep convection and the extratropical upward propagating Rossby waves. To reach 
our aim we take the advantage of a long numerical simulation to explore the relevant teleconnections, which can be plausible but hard to extract from the shorter record of reanalysis.

\section{Data and methodology}

\section{a. MPI-ESM-MR model}

We have analyzed southern winter (July, August, and September) monthly mean data covering a period of 210 years of the CMIP5 preindustrial control (piControl) simulation of the mixed-resolution (MR) version of the Max Planck Earth System Model (MPI-ESM-MR) (Giorgetta et al. 2013; Schmidt et al. 2013). The atmospheric component of this coupled atmosphere ocean model, ECHAM6, uses a spectral truncation at wavenumber 63 and an associated Gaussian grid of approximately $1.9^{\circ}$ resolution in longitude and latitude. The vertical grid has 95 hybrid sigma pressure levels resolving the atmosphere from the surface up to the center of the uppermost layer at $0.01 \mathrm{hPa}$. This grid has a nearly constant vertical resolution of $700 \mathrm{~m}$ from the upper troposphere to the middle stratosphere, and the resolution is better than $1 \mathrm{~km}$ at the stratopause (Fig. 1 in Schmidt et al. 2013). This vertical resolution enables the simulation of large-scale tropical waves and wave-mean flow interactions, which allows ECHAM6 to internally generate a realistic QBO (Krismer et al. 2013; Krismer and Giorgetta 2014). Krismer et al. (2013) found that the QBO generated by MPI-ESM-MR compares well with that from the ERA-40 with respect to the period, vertical extent, and amplitude in the lower stratosphere. However, at altitudes higher than the 40-hPa level the simulated QBO shows an amplitude $50 \%$ greater than in ERA-40.

For the model analysis, cloud area fraction at $100 \mathrm{hPa}$ has been considered as an indirect measurement of deep convection. In the model, clouds at this level are generated by the outflow of cloud condensate from the parameterized deep convective updrafts. Figure 1a shows that the climatological maximum for August occurs over the western Pacific and eastern Indian Ocean. Then, in order to study the response to deep convection over this region, we have defined winters with high and low cloudiness amount (CL-high and CL-low), according to the value of $100-\mathrm{hPa}$ cloud area fraction averaged over $0^{\circ}-25^{\circ} \mathrm{N}$ and $80^{\circ} \mathrm{E}-180^{\circ}(\mathrm{CL})$ above the 75 th or below the 25th percentile, respectively. For the purpose of removing a possible ENSO interference, which is realistically simulated by the model (Jungclaus et al. 2013) and has a strong impact on deep convection, we have performed the analysis for ENSO-neutral conditions.
Thus it only includes those months that meet the additional requirement of being characterized by SST anomalies between $-1^{\circ}$ and $1^{\circ} \mathrm{C}$ over the Niño-3.4 region (similar results were obtained for a SST threshold of $\pm 0.5^{\circ} \mathrm{C}$ ). Following this criterion, we obtained 46 (47) cases classified as CL-high (CL-low) for August (Table 1). Figure $1 \mathrm{~b}$ depicts the vertical profile of August cloud area fraction anomalies for CL-high minus CL-low. It shows that differences peak at $110 \mathrm{hPa}$, where they reach $8 \%$, and sharply decrease downward and upward, keeping at significantly lower values through the entire troposphere. This means that changes associated with this classification are related to deep convection variability. Finally, Figs. $1 \mathrm{c}$ and $1 \mathrm{~d}$ show CL-high minus CL-low differences for cloud area fraction at $100 \mathrm{hPa}$ and for precipitation. Given that precipitation is a proxy for convection, which is possibly deep in these tropical regions, consistent differences between Figs. 1c and $1 \mathrm{~d}$ demonstrate the link between convection and cloud area fraction and gives robustness to our interpretation of cloud area fraction anomalies at $100 \mathrm{hPa}$ in terms of deep convection variability. CL-high minus CL-low differences of surface temperature for August (Fig. 1e) show that stronger deep convection is linked to a generalized warming of the northern tropical Pacific Ocean with differences reaching values around $0.3^{\circ}$ and $0.6^{\circ} \mathrm{C}$ over the western and eastern parts, respectively. Another noticeable region seems to be northern India and China where temperature differences reach $1^{\circ} \mathrm{C}$.

The choice of the level used to define the QBO phases has been made with the aim of maximizing the QBO signature on deep convection. To determine it, we correlated southern winter zonal mean cloud area fraction at $100 \mathrm{hPa}$ averaged between latitudes $5^{\circ} \mathrm{S}$ and $5^{\circ} \mathrm{N}$ with zonal mean zonal wind averaged about the same latitude band at several pressure levels between 100 and $10 \mathrm{hPa}$. Maximum correlation values were achieved for the zonal wind at $70 \mathrm{hPa}(r=-0.41$ respectively, $p<0.05)$. This corresponds with the physical expectation that QBO jets need to be well defined close to the tropopause so that the adiabatic cooling or warming of the downward branch of the secondary circulation can effectively influence the $100-\mathrm{hPa}$ level. Thus, in this study, the QBO easterly (E-QBO) and westerly phase (W-QBO) correspond to those cases in which the zonal mean zonal wind at the equator at $70 \mathrm{hPa}$ is below $-7 \mathrm{~m} \mathrm{~s}^{-1}$ and above $+7 \mathrm{~m} \mathrm{~s}^{-1}$, respectively (similar results were obtained for E-QBO/W-QBO defined as $\pm 5 \mathrm{~m} \mathrm{~s}^{-1}$ at $70 \mathrm{hPa}$ ). Following this criterion and the additional requirement of ENSO-neutral conditions, we obtained 47 (31) cases for E-QBO (W-QBO) for August (Table 1) with an average magnitude of easterly and westerly jets at $70 \mathrm{hPa}$ reaching -14 and $+12 \mathrm{~ms}^{-1}$, 
(a) CL Climatology

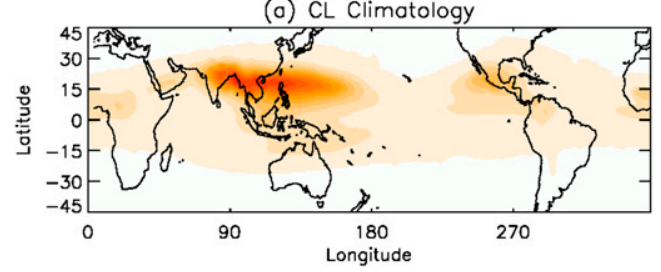

(c) $\mathrm{CL} C L-$ high $-\mathrm{CL}-$ low

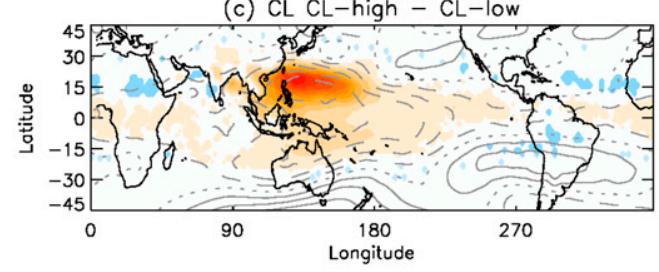

(d) precip $\mathrm{CL}$-high - $\mathrm{CL}$-low
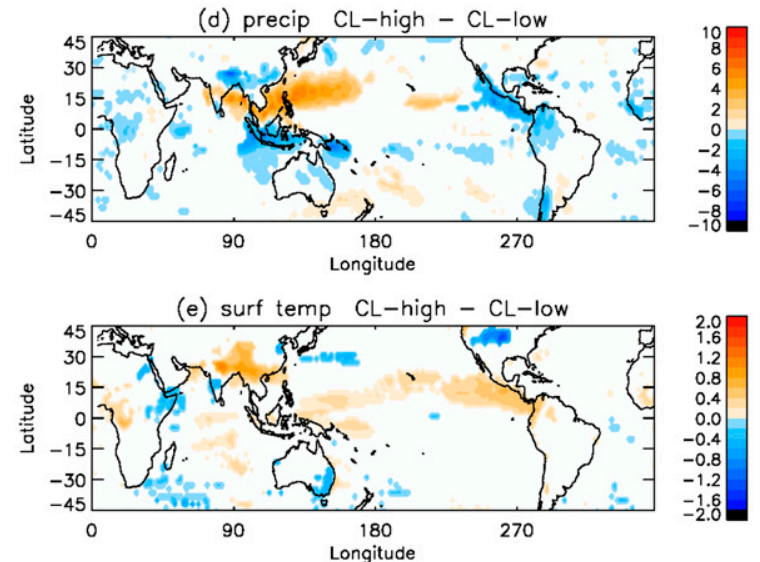
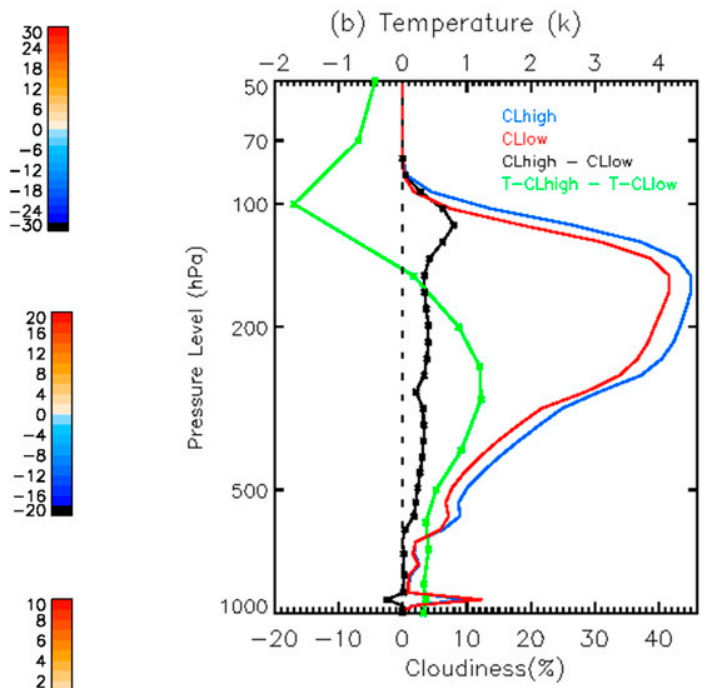

FIG. 1. MPI-ESM-MR results for (a) climatological mean field of August cloud area fraction at $100 \mathrm{hPa}(\%)$. (b) August cloud area fraction averaged over $0^{\circ}-25^{\circ} \mathrm{N}, 80^{\circ} \mathrm{E}-180^{\circ}$ for CL-high (blue) and CL-low (red), and CLhigh minus CL-low differences for cloud area fraction (black) and temperature (green) averaged over the same region. Dots are depicted at levels where differences are significant at the 95\% confidence level. (c)-(e) CL-high minus CL-low differences for August cloud area fraction (\%) and temperature [contour interval is $0.5^{\circ} \mathrm{C}$; solid (dashed) lines indicate positive (negative) differences] at $100 \mathrm{hPa}$, precipitation $\left(\mathrm{kg} \mathrm{m}^{-2} \mathrm{day}^{-1}\right)$, and surface temperature $(\mathrm{K})$, respectively. Only significant regions at $95 \%$ are shaded.

respectively (not shown). These values agree well with those obtained for ERA-Interim following the same procedure, for which the easterly and westerly jets reach values of around -17 and $+14 \mathrm{~m} \mathrm{~s}^{-1}$ at $70 \mathrm{hPa}$ (not shown).

As mentioned above, we have analyzed data covering from July to September. Nevertheless, the exposition of our results are based on August, for which the analyzed linkages are generally stronger, and not on the southern winter mean. Results obtained for separated southern winter months are not always comparable and differences among them give rise to a loss of magnitude and statistical significance for the winter mean. Either way, intrawinter changes are discussed throughout the paper

TABLE 1. Number of cases included in each sample for August and for MPI-ESM-MR and ERA-Interim.

\begin{tabular}{|c|c|c|c|c|c|}
\hline \multicolumn{6}{|c|}{ MPI-ESM-MR } \\
\hline Total number & 210 & E-QBO & 47 & W-QBO & 31 \\
\hline CL-high & 46 & E-QBO + CL-high (E-high) & 17 & W-QBO + CL-high (W-high) & 3 \\
\hline CL-low & 47 & E-QBO + CL-low (E-low) & 9 & $\mathrm{~W}-\mathrm{QBO}+\mathrm{CL}-\mathrm{low}$ & 13 \\
\hline CL-ntr & 48 & E-QBO + CL-ntr (E-ntr) & 9 & W-QBO + CL-ntr (E-ntr) & 5 \\
\hline \multicolumn{6}{|c|}{ ERA-Interim } \\
\hline Total number & 40 & $T$-low & 8 & $T$-high & 7 \\
\hline & & E-QBO & 5 & W-QBO & 7 \\
\hline
\end{tabular}


(a) temp T-low - T-high

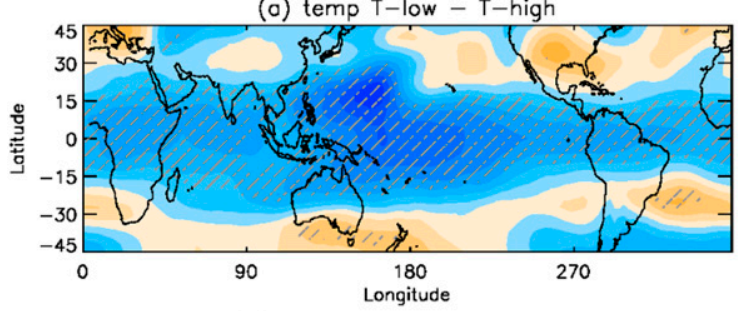

(b) temp $2 \mathrm{~m} \mathrm{~T}$-low - T-high

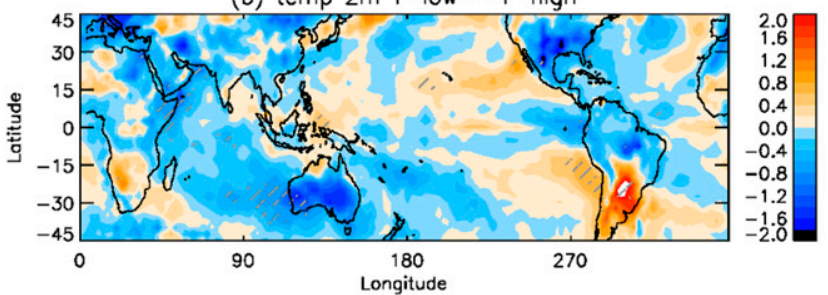

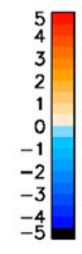

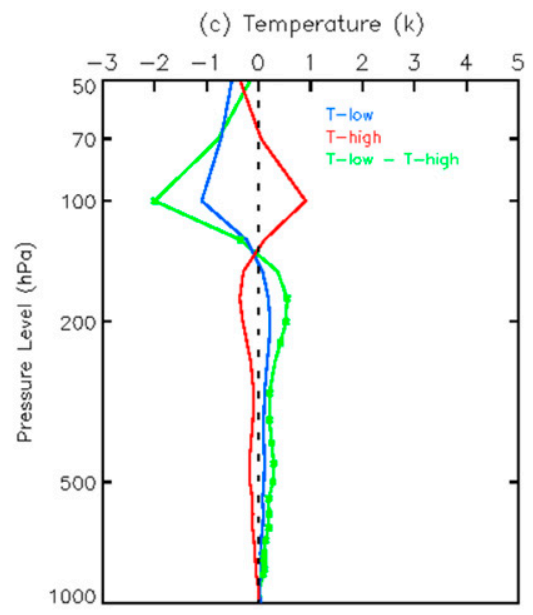

FIG. 2. ERA-interim $T$-low minus $T$-high differences for (a) August temperature at $100 \mathrm{hPa}\left({ }^{\circ} \mathrm{C}\right)$ and (b) air temperature at $2 \mathrm{~m}\left({ }^{\circ} \mathrm{C}\right)$. Stippling indicates significance at the $95 \%$ confidence level. (c) ERA-interim results for August temperature averaged over $0^{\circ}-25^{\circ} \mathrm{N}, 80^{\circ} \mathrm{E}-180^{\circ}$ for $T$-low (blue), $T$-high (red), and $T$-low minus $T$-high differences. Dots are depicted at levels where differences are significant at the $95 \%$ confidence level.

and the corresponding figures have been included in the online supplemental material.

\section{b. ERA-Interim reanalysis}

The model results in this study are compared to ERAInterim reanalysis data (Dee et al. 2011) covering the period 1979-2018. By contrast with the analysis performed from MPI-ESM-MR data, for which cloud area fraction at $100 \mathrm{hPa}$ is used as an indirect measurement of deep convection, for ERA-Interim we have used temperature at $100 \mathrm{hPa}$ over the region of maximum deep convection. As shown in Figs. 1b and 1c, a higher value of cloud area fraction at $100 \mathrm{hPa}$ produces a cooling that maximizes at around the same level. Thus, in order to avoid a variable like cloud area fraction, which is not assimilated into the reanalysis but predicted by the model, we chose temperature. Then we have defined winters with high or low temperature ( $T$-high and $T$-low) according to the value of $100-\mathrm{hPa}$ temperature anomalies averaged over $0^{\circ}-25^{\circ} \mathrm{N}$ and $80^{\circ} \mathrm{E}-180^{\circ}$ (CL) above the 75 th or below the 25 th percentile, respectively. Additionally, with the aim of removing a possible ENSO interference, we have only considered those months meeting ENSO-neutral conditions as they were previously defined. Following these criteria, the number of $T$-high or $T$-low cases range between 6 and 10 cases for the SH winter months (Table 1). Figure 2a shows that $T$-low minus $T$-high differences at $100 \mathrm{hPa}$ for August peak over the western Pacific, at around $15^{\circ} \mathrm{N}$. This is the region that also shows the strongest enhancement of deep convection together with the strongest cooling in Fig. 1c for MPI-ESM-MR. Furthermore,
Fig. 2c represents the vertical profile of $T$-low minus $T$-high differences for temperature during August. Similarly to Fig. $1 \mathrm{~b}$ for MPI-ESM-MR data, it shows that temperature differences peak at $100 \mathrm{hPa}$ and decrease downward and upward, keeping at significantly lower values through the entire troposphere, which supports the fact that changes associated with this temperature classification are related to deep convection variability. Figure $2 \mathrm{~b}$ displays $T$-low minus $T$-high differences for 2-m air temperature. Similarly to Fig. 1e for the model surface temperature, it shows a generalized warming of the northern tropical Pacific Ocean linked to deep convection enhancement, although very few areas show significant values. By contrast with model results, a significant warming is found over the southern part of the tropical eastern Pacific while nonsignificant temperature changes are observed over China.

With regard to the definition of the QBO phases we used the same criteria as for MPI-ESM-MR model but relaxed the wind speed threshold to $\pm 5 \mathrm{~m} \mathrm{~s}^{-1}$ in order to keep a larger number cases. ENSO-neutral conditions were also imposed as an additional requirement, which led to a number of E-QBO and W-QBO cases ranging between 4 and 10 depending on the month (Table 1).

\section{SH extratropical response to tropical deep convection in MPI-ESM-MR}

As has been described in previous studies, the tropical response to the climatological deep convection maximum is characterized by a Matsuno-Gill-type RossbyKelvin wave couplet (Gill 1980; Dima et al. 2005). This is 


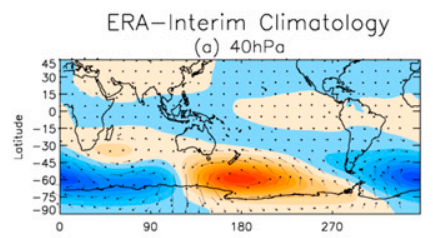

(b) $100 \mathrm{hPa}$.

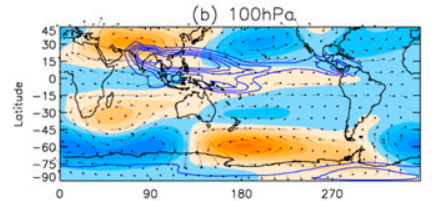

(c) $200 \mathrm{hPo}$

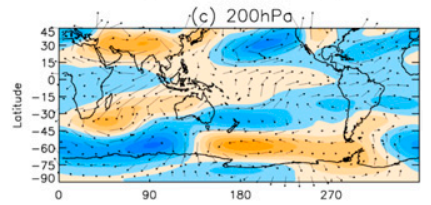

(d) $50,0 \mathrm{hPa}$
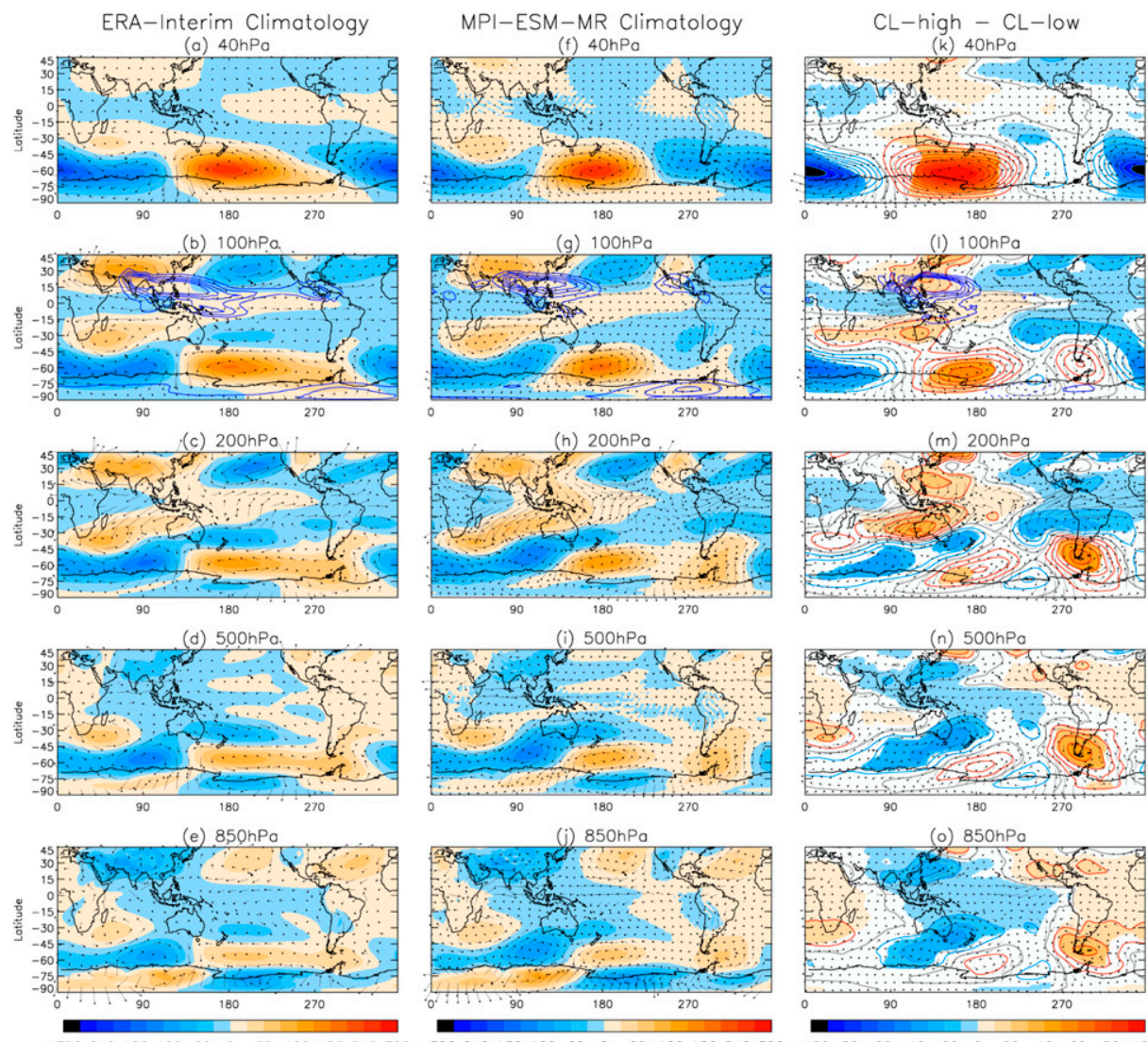

(m) $200 \mathrm{hPo}$
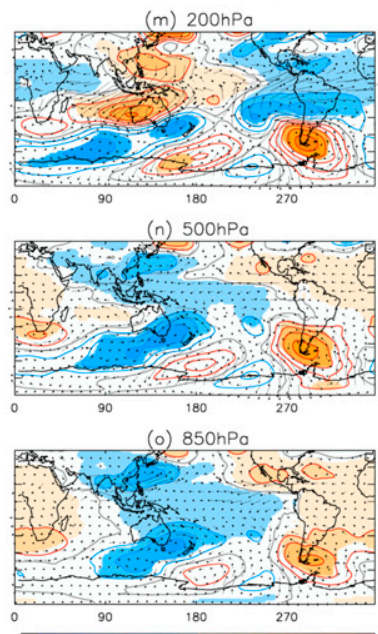

$-100-80-60-40-20 \quad 0 \quad 20 \quad 40 \quad 60 \quad 80 \quad 100$
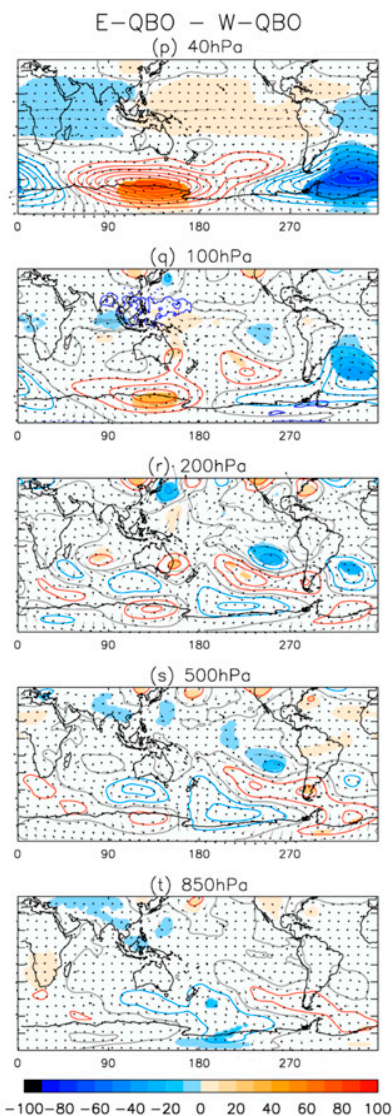

FIG. 3. (a)-(e) ERA-Interim climatological eddy fields of geopotential height (m) (color shades) and wind (arrows) for August at different levels between 850 and $40 \mathrm{hPa}$ together with cloud area fraction (dark blue contours at intervals of $5 \%$ ) at $100 \mathrm{hPa}$ averaged over the period 1979-2018. (f)-(j) As in (a)-(e), but for 210-yr MPI-ESM-MR model output. (k)-(o),(p)-(t) As in (f)-(j), but for MPI-ESMMR CL-high minus CL-low and E-QBO minus W-QBO differences of the eddy fields, respectively. Positive, zero, and negative geopotential height differences are represented by red, gray, and light blue contours, respectively, while color shades show those that are significant at the $95 \%$ confidence level. Contour interval for cloud area fraction differences is $2 \%$ while for geopotential height is $10 \mathrm{~m}$ with no zero line.

clearly observed in Fig. 3 (first and second columns), which evidences the good agreement between ERAInterim and the model simulation of the climatological eddy geopotential height and wind fields at different tropospheric and stratospheric levels for August. Thus, at $100 \mathrm{hPa}$, a positive pressure band extends over the equatorial Pacific where the zonal wind diverges out of the region of convection. As a consequence a westerly wind anomaly is observed to the east while easterlies are found at, and to the west of, the heating region, giving rise to two anticyclones at about $30^{\circ}$ north and south of the equator, over South Asia and China in the Northern Hemisphere and the Indian Ocean in the Southern Hemisphere. Because the region of maximum convection is north of the equator, the Northern Hemisphere part of the couplet is more developed. In addition, Fig. 3 (first and second columns) shows that the response to deep convection is not restricted to the tropical UTLS.
In the Southern Hemisphere it is consistent with a poleward propagation of subtropical Rossby waves initiated by the anticyclone at $30^{\circ} \mathrm{S}$. This is clearly observed in panels corresponding to tropospheric levels of Fig. 3 (first and second columns), which show a wave train over the Indian Ocean consistent with a southeastward propagation of wave activity from the tropics to the high latitudes of the Pacific Ocean. This is in agreement with previous studies showing evidence of southeastward propagation of tropical stationary waves occurring, during the southern winter, through the Indian Ocean from South Australia to the high latitudes of the Pacific Ocean (Karoly et al. 1989; Quintanar and Mechoso 1995a; Inatsu and Hoskins 2004). According to this poleward wave propagation from the tropics, it would be expected that high-latitude eddies were modulated by tropical deep convection variability. Thus, taking advantage of the long numerical experiment, we used the 
(a) $\mathrm{CL}$-high $-\mathrm{CL}-$ low

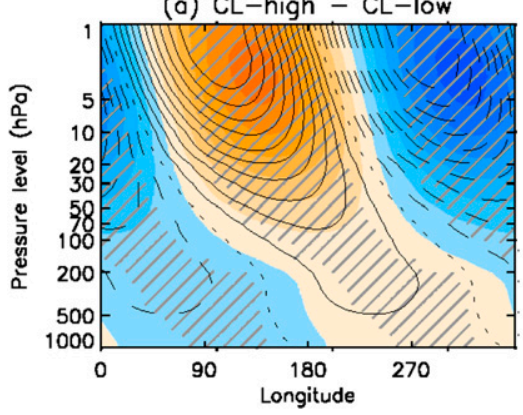

(b) $\mathrm{E}-\mathrm{QBO}-\mathrm{W}-\mathrm{QBO}$

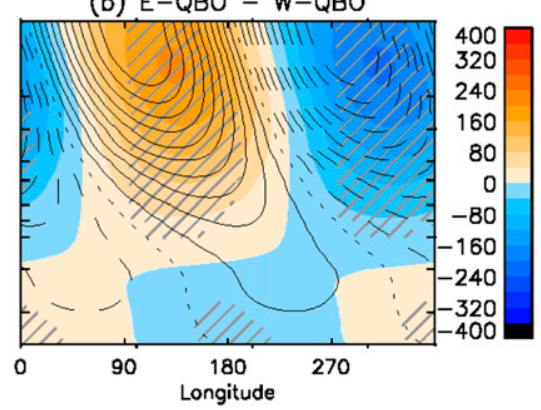

(c)

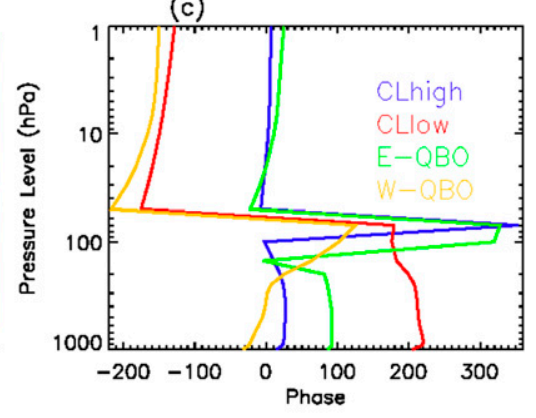

FIG. 4. Vertical cross section of the longitudinal distribution of August wave-1 eddy geopotential height anomalies averaged over $50^{\circ}-$ $75^{\circ} \mathrm{N}$, as obtained from the MPI-ESM-MR model, for (a) CL-high minus CL-low and (b) E-QBO minus W-QBO, superimposed on the mean climatology (contour interval is $50 \mathrm{~m}$ ). (c) Vertical evolution of the phase difference between the wave- 1 anomalies for CL-high, CL-low, E-QBO, and W-QBO and the climatological wave 1. Stippling indicates significance at the $95 \%$ confidence level.

model data to explore this possible modulation. The third column of Fig. 3 (the fourth column of Fig. 3 is discussed in section 4) shows CL-high minus CL-low differences (see section 2 for further details) for the eddy fields of geopotential height and wind at different tropospheric and stratospheric levels for August together with cloud area fraction differences at $100 \mathrm{hPa}$. Consistently, this figure shows that geopotential height differences exhibit high-latitude eddy anomalies that resemble stationary eddies observed in the model climatological mean (Fig. 3, second column), which evidences that the strengthening of deep convection over the tropical northwestern Pacific gives rise to an enhancement of the tropical and subtropical climatological stationary waves and also to those at high latitudes. This applies both to the upper- and lower-tropospheric levels and also to the stratosphere (only shown for $40 \mathrm{hPa}$ ) and provides further evidence of the key role of tropical deep convection over the climatological maximum in the generation and modulation of the high latitude stationary waves in the troposphere and the stratosphere. This is consistent with previous studies that attributed the maintenance of substantial tropospheric highlatitude stationary wavenumber- 1 eddies to the forcing of wave activity from lower latitudes (Quintanar and Mechoso 1995b). Inatsu and Hoskins (2004) showed that the SH stationary waves are related to tropical SST zonal asymmetries. Thus, they suggested that SH stationary waves are part of a Rossby wave train forced by summer monsoonal asymmetries that produce an anticyclone over the tropical Indian Ocean, which gives rise to the Rossby wave train. Our results are consistent with the anticyclone over the tropical Indian Ocean as the perturbation that originates the climatological SH stationary waves, and, in addition, point to tropical deep convection in the region of the climatological maximum, the tropical northwestern Pacific, as the forcing giving origin to this anticyclone and, consequently, to SH stationary waves. Surface temperature anomalies related with the enhancement of deep convection over the climatological maximum are depicted in Fig. 1e and show a generalized warming of the northern tropical Pacific Ocean, northern India, and China.

Figure $3 \mathrm{k}$, for $40 \mathrm{hPa}$, shows that wave- 1 eddy anomalies in the extratropical UTLS reach the stratosphere. The upward propagation of the wave- 1 eddy anomalies through the winter stratosphere is evidenced in Fig. 4a (Fig. 4b is discussed in section 4), which shows the vertical cross section of the longitudinal distribution of wave-1 eddy geopotential height anomalies averaged over $50^{\circ}-75^{\circ} \mathrm{S}$ for CL-high minus CL-low, superimposed on the mean climatology. Here it is evident that deep convection substantially modulates the amplitude of the wave- 1 climatological eddy field, with differences amounting to $60 \%$ of the climatological values. On the other hand, Fig. $4 \mathrm{c}$ shows that CL-high wave-1 eddy anomalies are in phase with the climatological wave 1 in the stratosphere while there is a phase difference of around $130^{\circ}$ with CL-low wave- 1 eddy anomalies. Thus, the enhancement of deep convection occurring during CL-high gives rise to a wave- 1 eddy anomaly at high southern latitudes that interferes constructively and, consequently, reinforces the climatological eddy field. Furthermore, the similarity between the climatological eddy field and eddy anomalies shown in Fig. 3 (left and middle columns) and in Fig. 4a gives further evidence of the role of tropical deep convection in the region of the climatological maximum as a main forcing of southern winter stationary waves of the extratropical troposphere and, also, of the stratosphere. The connection between tropical deep convection and stratospheric stationary waves is also apparent in Fig. 5a depicting CL-high minus CL-low differences of the Eliassen-Palm (EP) flux components (EPy, EPz) and divergence (EPdiv). 
(a) $\mathrm{CL}$-high $-\mathrm{CL}-$ low
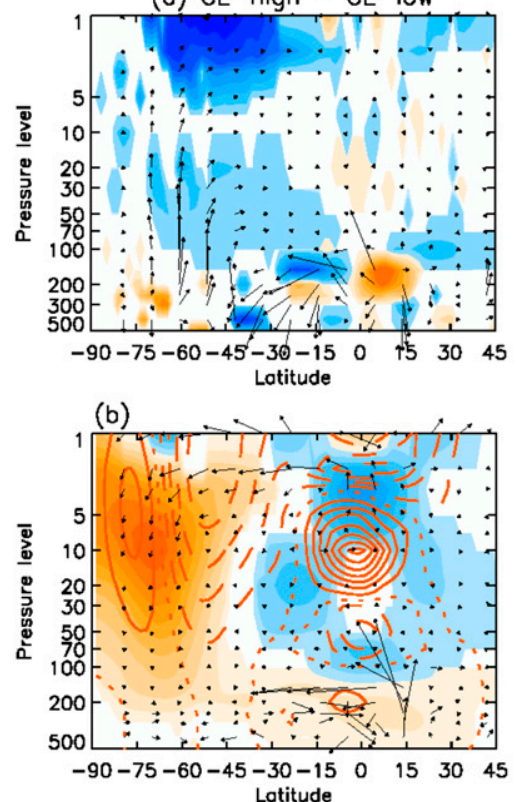

(c) $\mathrm{E}-\mathrm{QBO}-\mathrm{W}-\mathrm{QBO}$
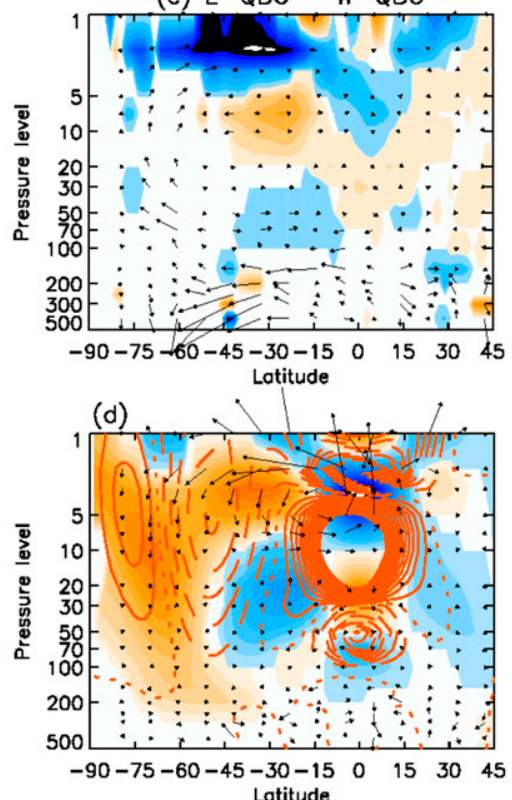
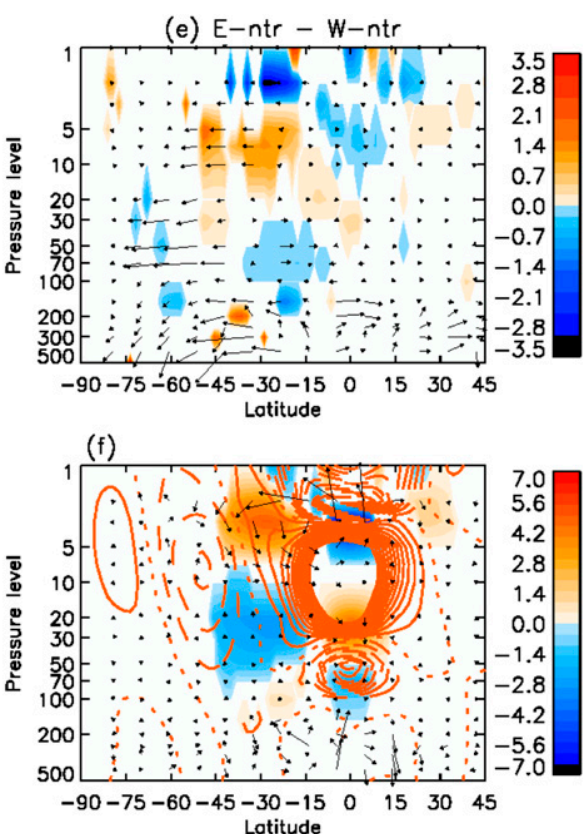

FIG. 5. (left) CL-high minus CL-low differences, as obtained from the MPI-ESM-MR model, of (a) EP flux vectors (arrows) and EP flux divergence in $\mathrm{m} \mathrm{s}^{-1} \mathrm{day}^{-1}$ (color shades) and (b) residual circulation (arrows), temperature in $\mathrm{K}$ (color shades), and zonal wind (red contours). Contour interval is $2.5 \mathrm{~m} \mathrm{~s}^{-1}$. Only significant regions at $95 \%$ are shaded. (middle),(right) As in left, but for (c),(d) E-QBO minus $\mathrm{W}-\mathrm{QBO}$ and (e),(f) E-ntr minus $\mathrm{W}$-ntr differences, respectively.

Differences in the EP flux show poleward anomalies at the tropical UTLS that extend to extratropical latitudes in the $\mathrm{SH}$, indicating that the climatological northward wave propagation (not shown) weakens during CL-high. As we have previously seen, deep convection and, consistently, the climatological tropical wave pattern, reinforce during CL-high. This led to an enhancement of the southward propagation of waves from the tropical UTLS consistent with the observed differences in the meridional component of the EP flux. On the other hand, upward EP flux anomalies at high latitudes in both the troposphere and stratosphere indicate that the climatological upward wave propagation strengthens (weakens) during CL-high (CL-low). Consistently, differences in the EP flux divergence (Fig. 5a) show negative significant values that extend to southern polar latitudes, meaning stronger EP flux convergence at the upper winter stratosphere for CL-high. Stronger EP flux convergence involves an enhancement of the BrewerDobson circulation and a warming of the polar winter stratosphere. Figure 5b (Figs. 5c-f are discussed in section 4) shows August temperature differences for CL-high minus CL-low reaching $5^{\circ} \mathrm{C}$ at around $10 \mathrm{hPa}$ at high southern latitudes occurring together with a strengthening of the southward flow at upper levels and of the downward flow through the polar stratosphere, thus causing adiabatic heating. Consistent anomalies are observed for the zonal wind, which shows a dipole structure with positive (negative) differences southward (northward) of $70^{\circ} \mathrm{S}$ that reach $5(10) \mathrm{m} \mathrm{s}^{-1}$ in the upper stratosphere.

Regarding the intrawinter changes, consistent results were obtained for July and September (see Fig. S1 in the online supplemental material), giving evidence for a linkage between tropical deep convection over the region of the climatological maximum and the extratropical southern winter stratosphere, occurring during July-September, in such a way that stronger deep convection causes an enhancement of the Brewer-Dobson circulation and a warming of the stratospheric polar vortex.

\section{Role of the QBO-deep convection linkage in MPI-ESM-MR}

\section{a. The $Q B O$ modulation of convection}

As was described in the previous section, Fig. 5b shows evidence of southern polar vortex variability linked to tropical deep convection. However, this figure also shows a QBO signature with a westerly wind maximum at $10 \mathrm{hPa}$ and an easterly wind maximum between 70 and $50 \mathrm{hPa}$. Thus, in spite of the fact that this composite difference is only based on cloud cover, and implicitly on deep convection intensity, it already sorts the 


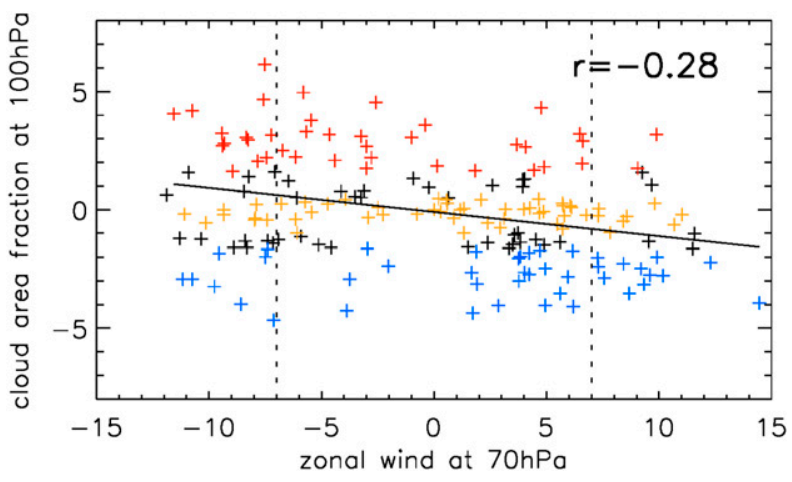

FIG. 6. Scatterplot of MPI-ESM-MR zonal mean zonal wind over the equator at $70 \mathrm{hPa}$ vs cloud area fraction anomalies at $100 \mathrm{hPa}$ averaged over $0^{\circ}-25^{\circ} \mathrm{N}, 80^{\circ} \mathrm{E}-180^{\circ}$ latitude for August. Red (blue) crosses represent those cases classified as CL-high (CL-low) according to the value of cloud area fraction temporal anomalies above the 75th (below the 25th) percentile while yellow ones represent those between the 37.5 th and 62.5 th percentiles, classified as CL-ntr. The remaining cases are depicted in black. All cases considered meet ENSO-neutral conditions. Left and right dashed vertical line represent the threshold used to define E-QBO and $\mathrm{W}-\mathrm{QBO}$ cases, respectively. The solid line depicts the linear regression line computed for all points, and $r=0.25$ is the correlation coefficient, which is statistically significant at the $95 \%$ confidence level.

QBO phases relatively well. This indicates that CL variability and the QBO are highly coupled, as confirmed by Fig. 6, which shows that there is a significant linear relationship $(r=0.28, p<0.05)$ between CL and QBO winds at $70 \mathrm{hPa}$. Figure 7a depicts QBO-related differences for cloud area fraction at $100 \mathrm{hPa}$. As expected from Fig. 6, this figure shows a significant QBO signature, which is mainly located over the western $\mathrm{Pa}$ cific at latitudes between $5^{\circ} \mathrm{S}$ and $15^{\circ} \mathrm{N}$ and reaches maximum values of around $5 \%$. These differences are not as low as it may seem when compared with the climatological values over the region, which reach maximum values below $25 \%$ (Fig. 1a). Figure 7a recalls Fig. 1c for CL-high minus CL-low differences, although cloud area fraction anomalies related to the QBO are shifted equatorward and are smaller by a factor of 4 .

The depth of the QBO signature on convection is depicted in Fig. 7b. It shows that QBO-related differences peak at $110 \mathrm{hPa}$ where they are slightly above $3 \%$. However, they fall sharply to zero at levels below and above and remain negligible downward through the entire troposphere. In spite of this maximum at $110 \mathrm{hPa}$, the spatial pattern of the differences at this level (not shown) reveals that the region where these are statistically significant is smaller than at $100 \mathrm{hPa}$ (Fig. 7a). Either way, these results show that in this simulation QBO effects on convection are restricted to a relatively thin layer of the UTLS, which explains why the QBO

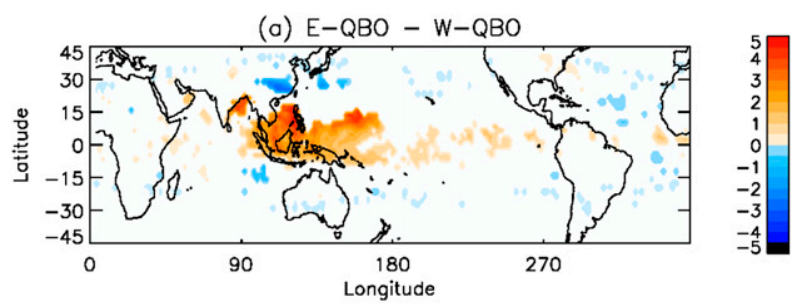

(b) Temperoture (k)

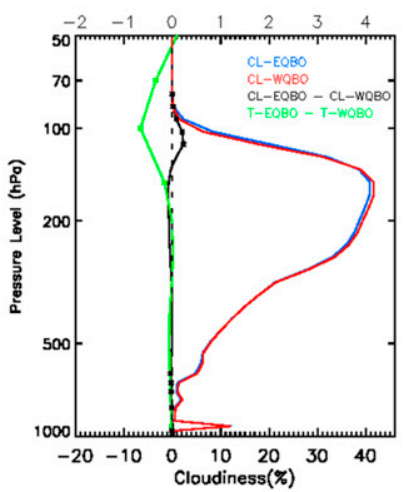

FIG. 7. (a) As in Fig. 1c, but for E-QBO minus W-QBO differences. (b) As in Fig. $1 \mathrm{~b}$, but averaged over the area $5^{\circ} \mathrm{S}-15^{\circ} \mathrm{N}, 90^{\circ} \mathrm{E}-$ $180^{\circ}$ for E-QBO (blue), W-QBO (red), E-QBO minus W-QBO differences (black), and temperature averaged over the same region (green). Dots are depicted at levels where differences are significant at the $95 \%$ confidence level.

signature on variables that accounts for the effects on the atmosphere as a whole, as outgoing longwave radiation or precipitation, gave nonsignificant results (not shown). Possibly the earlier reported weakness of the simulated QBO jets near the tropopause, in comparison with the QBO in ERA-Interim, also leads to an underestimation of the QBO effects on the deep convection.

A significant enhancement of tropical deep convection during E-QBO is also evident in July and September (Fig. S2). Nevertheless, this is weaker than in August, especially in July, when it is only observed over the tropical eastern Indian Ocean.

\section{b. QBO-SH polar vortex pathway}

Once we have evidence of the QBO modulation of deep convection over the region of the climatological maximum the question arises as to whether this will lead to a QBO impact on tropical and extratropical stationary waves. To assess this possibility we computed E-QBO minus W-QBO differences for the eddy fields of geopotential height and wind at different tropospheric and stratospheric levels for August together with cloud area fraction differences at $100 \mathrm{hPa}$ (Fig. 3, right column). This figure is consistent with an enhancement of 
the climatological Rossby-Kelvin wave couplet observed in the tropics at $100 \mathrm{hPa}$ during E-QBO, when deep convection over the climatological maximum strengthens. Although wave anomalies are statistically significant over few regions for levels from 100 to $500 \mathrm{hPa}$, Figs. $3 \mathrm{q}-\mathrm{s}$ suggest a poleward propagation of tropical eddy anomalies over the Indian Ocean, giving rise to a wave train consistent with a southeastward propagation of wave activity reaching polar latitudes over the Antarctic. A second wave train indicates that waves are refracted equatorward over the Pacific Ocean in agreement with Quintanar and Mechoso (1995a), who observed similar wave propagation patterns in the southern winter hemisphere. Giorgetta et al. (1999) also show the formation of wave trains in the winter southern troposphere as a response to the heat release during the QBO modulation of deep convection over the tropical western Pacific. Although slightly shifted eastward, these wave trains exhibit a very similar structure and a barotropic nature that is also observed in the wave trains of Fig. 3 (fourth column). However, the QBO impact is stronger in the stratosphere. Figure $3 p$, for $40 \mathrm{hPa}$, demonstrates that it is the wave- 1 component of the QBO eddy anomalies that propagates upward to the stratosphere, as is expected from the fact that only the longest waves are able to propagate beyond the troposphere into the stratosphere. To assess how this QBO wave-1 eddy anomaly interacts with the climatological eddy, Fig. 4b depicts the vertical cross section of the longitudinal distribution of wave- 1 eddy geopotential height anomalies averaged over $50^{\circ}-75^{\circ} \mathrm{S}$ for E-QBO minus W-QBO, superimposed on the mean climatology. It clearly shows the occurrence of a wave-1 eddy anomaly at high southern latitudes that propagates through the stratosphere interfering constructively with the climatological eddy fields during the E-QBO phase (Fig. 4c) This is consistent with an enhancement of the climatological wave-1 eddy during E-QBO, when deep convection is stronger, suggesting that the interference of wave- 1 eddy anomalies propagating through the southern winter stratosphere for different QBO phases are highly influenced by the QBO modulation of deep convection.

The QBO modulation of the wave-1 climatological eddy is also evident in Fig. 5c, which depicts differences between E-QBO and W-QBO of the EP flux and its divergence (EPdiv). Stronger convection during E-QBO is related to an enhanced propagation of wave activity from the tropical UTLS to the polar winter troposphere and upward through the polar stratosphere giving rise to a stronger EP flux convergence at the upper stratosphere at middle and high latitudes. This generates an enhancement of the Brewer-Dobson circulation and a warming of the polar stratosphere. Figure 5d shows QBO-related temperature differences in the stratosphere in high southern latitudes reaching $5^{\circ} \mathrm{C}$ occurring together with a strengthening of the southward flow at upper levels and of the downward flow through the polar stratosphere, thus causing adiabatic heating. Consistent anomalies are observed for the zonal wind that shows a dipole structure with positive (negative) differences southward (northward) of $70^{\circ} \mathrm{S}$ that reach 6 to $-10 \mathrm{~m} \mathrm{~s}^{-1}$ (Fig. 5d). QBO-related differences over the polar winter stratosphere are generally weaker than those strictly related to deep convection strength regardless of the QBO (Figs. 5d,b). This is consistent with deep convection anomalies linked to the QBO being weaker than those for CL-high minus CLlow (Figs. 7a and 1b), which involves that any climate pattern causing a stronger modulation of deep convection over the region of the climatological maximum could generate greater eddy anomalies at polar latitudes and modulate the climatological upward eddy flux in a more powerful way.

With the aim of further assessing to what extend QBO wave-1 eddy anomalies are linked to the modulation of deep convection, we computed QBO-related differences for "neutral deep convection" cases, that is, those with no significant modulation of deep convection (cloud area fraction anomalies in the marked area over the western Pacific between the 37.5th and 62.5th percentiles, CLntr). Out of 47 (31) months of August with E-QBO (W-QBO), 9 (5) cases occurred under Clntr conditions (Table 1), labeled as E-ntr (W-ntr). E-ntr minus W-ntr differences (not shown) were computed for the vertical cross section of the longitudinal distribution of wave-1 eddy geopotential height anomalies following the same procedure as for Fig. 4. In this case, in addition to the fact that the pattern of the eddy anomalies do not show a constructive interference with the climatological eddies, statistically significance strongly decreases. Furthermore, E-ntr minus W-ntr differences were also computed for the zonal mean fields (Figs. 5e,f). These results clearly show that differences in the polar winter stratosphere strongly weaken for all variables and, in most cases, turn to nonstatistically significant values. It could be argued that the low number of E-ntr or W-ntr cases makes it difficult to achieve significance; however, in addition to not being statistically significant, E-ntr minus W-ntr differences for temperature at midhigh latitudes are 3 times lower (for clarity purposes, nonsignificant temperature differences are not shown) than those observed for E-QBO minus W-QBO differences. Also, wind differences outside the QBO domain are significantly lower. Moreover, we computed differences for what we called "in phase" cases, those when E-QBO 

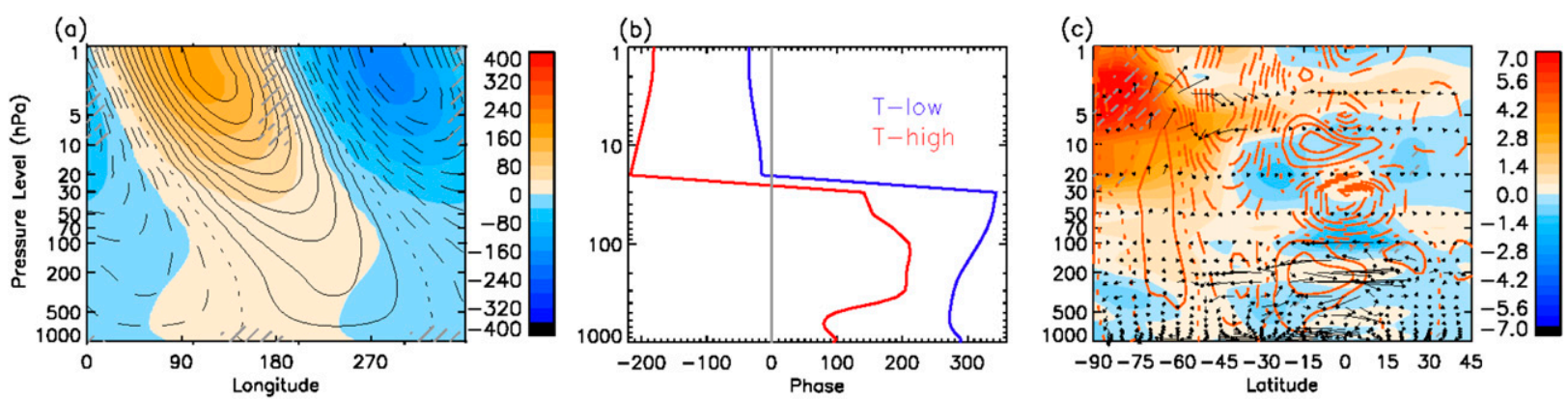

FIG. 8. ERA-Interim results for (a) vertical cross section of the longitudinal distribution of August wave-1 eddy geopotential height anomalies averaged over $50^{\circ}-75^{\circ} \mathrm{N}$ for $T$-low minus $T$-high superimposed on the mean climatology. (b) Vertical evolution of the phase difference between the wave- 1 anomalies for $T$-low (blue) and $T$-high (red) and the climatological wave 1 . (c) $T$-low minus $T$-high differences for August residual circulation (arrows), temperature in K (color shades), and zonal wind (red contours). Stippling indicates significance at the $95 \%$ confidence level.

(W-QBO) concurs with CL-high (CL-low) conditions (called E-high, with 17 cases, and W-low, with 13 cases; Table 1) and for the "out of phase" cases, those meeting the criteria for E-QBO (W-QBO) and CL-low (CLhigh) at the same time (called E-low, with 9 cases, and W-high, with 3 cases; Table 1). Only differences for E-high minus W-low led to statistically significant results, reproducing the wave pattern observed in Figs. 4 and 5 and, as could be expected, with differences reaching higher values. This evidences that the linkage between the QBO and the SH polar vortex can only be explained if we take into account the QBO modulation of deep convection. Therefore, these results describe a new path for QBO-southern polar vortex interaction during August in which the QBO modulation of deep convection plays a key role.

Regarding the intrawinter behavior, September results reveal a significant QBO impact on the $\mathrm{SH}$ polar vortex linked to deep convection, even though, as expected from a weaker QBO impact on CL during September, a weaker response of the $\mathrm{SH}$ polar vortex is observed (Fig. S3). Finally, even though July shows a significant QBO modulation of the polar vortex, it is not possible to establish whether or not this response is related to the QBO modulation of tropical deep convection since this QBO signature also appears under CL-ntr conditions.

\section{A comparison with ERA-Interim reanalysis}

In sections 3 and 4 we have established the linkages of 1) tropical deep convection variability and SH stationary waves, and of 2) QBO, tropical deep convection, and the $\mathrm{SH}$ winter polar vortex from a piControl experiment of the MPI-ESM-MR model. To assess these links from a dataset that includes observations, we have carried out the previous analysis using the ERA-Interim reanalysis.
Regarding the first linkage, ERA-Interim results support the occurrence of this relationship along the entire SH winter. Thus, Fig. 8a, depicting $T$-low minus $T$-high differences of wave- 1 geopotential height anomalies over $50^{\circ}-75^{\circ} \mathrm{S}$ for August, under ENSO-neutral conditions, reveals the occurrence of a wave- 1 eddy anomaly at high southern latitudes that propagates through the stratosphere and interferes constructively (Fig. 8b) with the climatological eddy fields when deep convection is stronger (under $T$-low conditions). Figure $8 \mathrm{c}$ shows a significant warming of the polar vortex during $T$-low with respect to $T$-high consistent with the enhancement of the upward propagation of climatological wave-1 eddies. Comparable results were found for July and September (Fig. S4), although July results are not statistically significant. Regarding the Brewer-Dobson circulation, ERA-Interim results show an enhancement of the downwelling at around $60^{\circ} \mathrm{S}$. However, even though the warming extends southward to the pole, positive vertical velocity differences are found around $75^{\circ} \mathrm{S}$. Taking into account that monthly averages of ERA-Interim vertical velocity for $\mathrm{SH}$ winter months also show an upwelling centered at these latitudes, we can considered that the observed positives differences involve a strengthening of the climatological pattern.

With respect to the second linkage, we first looked into the QBO signature on deep convection. It is difficult to assess this signature from temperature at $100 \mathrm{hPa}$, as the QBO modulates temperature at this level due to its secondary meridional circulation and independently of its potential impact on deep convection. Thus, despite its predictive nature, we have assessed this signature from cloud area fraction at $100 \mathrm{hPa}$. In this regard, E-QBO minus W-QBO differences for ENSO-neutral cases show a QBO signature that is generally of higher magnitude than in MPI-ESM-MR but hardly reaches statistical significance, and does so only in very few regions. 
Both ERA-Interim and model results show an enhancement of deep convection over the Pacific during E-QBO for August and September and over the eastern Indian Ocean for July (Fig. S2). However, a longer record would be necessary to determine the degree of agreement between both datasets. Neither has it been possible to establish a link between the QBO modulation of deep convection and the $\mathrm{SH}$ winter polar vortex in ERA-Interim. Thus, even though August and September results show a warming of the polar vortex, this is not statistically significant and the short data record makes it impossible to establish a relationship between this signature and that on cloud area fraction due to the fact that there are not enough cases to analyze the QBO impact on the wave- 1 eddy field under CL-ntr conditions.

\section{Discussion and conclusions}

Results from a 210-yr piControl experiment of the MPI-ESM-MR model provide evidence that tropical deep convection over the region of the climatological maximum plays a key role in the generation and modulation of southern winter high-latitude stationary waves. Our results therefore identify the location of the low-latitude origin of SH stationary waves first demonstrated by Mechoso et al. (1995) and thereafter supported by Inatsu and Hoskins (2004). Consistent with Inatsu and Hoskins (2004), our results show that the anticyclone over the tropical Indian Ocean leads to the Rossby wave train, giving rise to the climatological SH stationary waves. But, in addition, here we point to tropical deep convection in the region of the climatological maximum, the tropical northwestern Pacific and Southeast Asia, as the climatological thermal forcing that drives and modulates this anticyclone and, consequently, climatological SH stationary waves. Thus, Rossby waves generated at the UTLS by deep convection over this region propagate toward the extratropical southern winter hemisphere and upward through the winter stratosphere. As a consequence, stronger tropical deep convection reinforces stratospheric wave-1 climatological eddies, giving rise to a stronger Brewer-Dobson circulation and warmer polar winter stratosphere. Consistent results were found for the ERA-Interim reanalysis, which also show evidences of the linkage between tropical deep convection in the region of the climatological maximum and $\mathrm{SH}$ winter stationary waves and its impact on the polar vortex. Furthermore, we find that stronger deep convection over the climatological maximum is linked to higher surface temperature over the northern tropical Pacific, which suggests that a warming over this region could induce the observed response in the Brewer-Dobson circulation and the polar vortex of the southern winter hemisphere. This is consistent with previous studies relating warmer tropical SSTs with changes in SH wave activity inducing a warming of the SH polar vortex (Nishii and Nakamura 2004; $\mathrm{Hu}$ and $\mathrm{Fu} 2009$ ).

Once a linkage has been established between tropical deep convection and the polar winter stratosphere of the Southern Hemisphere, we asked if this could be a pathway for the QBO impact on the polar vortex. Model results show QBO easterlies (westerlies) in the lower stratosphere, above the tropical tropopause, associated with an increase (decrease) of cloudiness in the tropical UTLS, which is maximum at $100 \mathrm{hPa}$ and negligible below $200 \mathrm{hPa}$. The longitudinal distribution of the QBO signature on deep convection is highly asymmetric, being stronger where the climatology, regardless of the QBO phase, exhibits a more intense deep convection. Thus, during the austral winter, the QBO modulation of deep convection occurs mainly over the western Pacific at latitudes between $5^{\circ} \mathrm{S}$ and $25^{\circ} \mathrm{N}$. Although observable for all summer months, the QBO signature is stronger in August, when climatological values of $100-\mathrm{hPa}$ cloud area fraction are also higher, while it is quite weak in July. Even though the statistical significance is quite poor, ERA-Interim results are consistent with a QBO modulation of deep convection that maximizes in August over the western Pacific.

The length of the ERA-Interim data record is too short to explore the potential impact of the QBO modulation of convection on the SH polar vortex. However, MPI-ESM-MR results suggest that this modulation plays a fundamental role in the transmission of the QBO signature to the southern stratosphere during August and September. The following interactions are important for this linkage:

1) Deep convection over the climatological maximum enhances (weakens) during E-QBO (W-QBO), reinforcing (weakening) the tropical climatological Rossby-Kelvin wave couplet at the UTLS.

2) Eddy anomalies propagate southeastward to high latitudes where the wave- 1 component propagates upward through the stratosphere, interfering constructively (destructively) with the climatological wave-1 eddy during E-QBO (W-QBO).

3) Finally, in accordance with the wave-mean flow interaction theory, the meridional circulation enhances (weakens) and the polar vortex warms (cools) during E-QBO (W-QBO).

To test the sensitivity to the level used to define the QBO phases, Fig. 9 shows QBO-related differences in the southern polar stratosphere temperature (black) in 


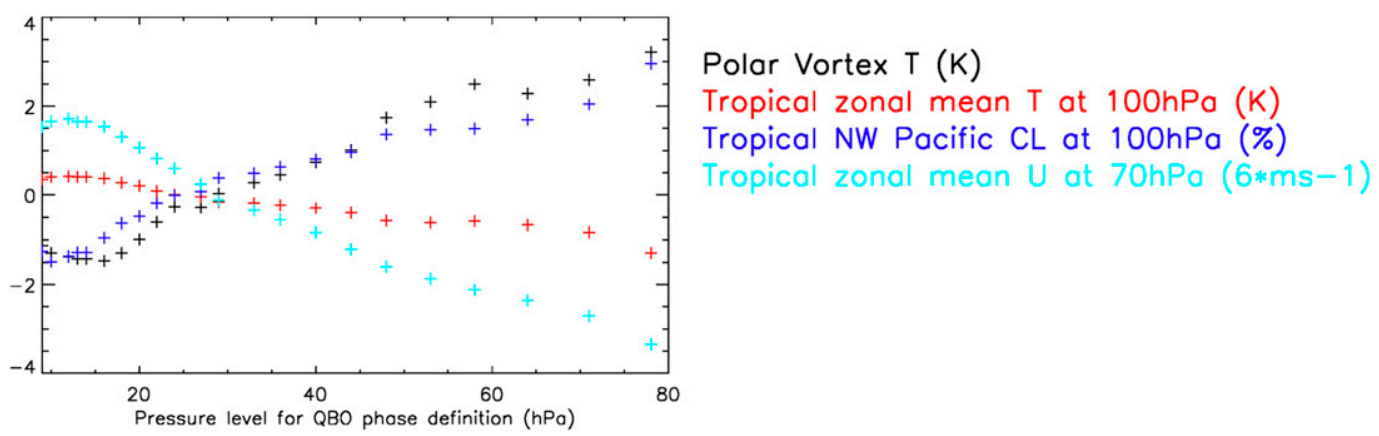

FIG. 9. August E-QBO minus W-QBO differences, as obtained from the MPI-ESM-MR model, in relation to the pressure level used to define the QBO phases, for zonal mean polar stratosphere temperature as the average over $80^{\circ}-50^{\circ} \mathrm{S}$ and $50-5 \mathrm{hPa}$ (black) together with differences in zonal mean zonal wind at $70 \mathrm{hPa}$ averaged over $5^{\circ} \mathrm{S}-5^{\circ} \mathrm{N}$ (values are divided by 6 ; light blue), zonal mean temperature at $100 \mathrm{hPa}$ averaged over $5^{\circ} \mathrm{S}-5^{\circ} \mathrm{N}$ (red), and cloud area fraction over the tropical western Pacific (dark blue) at $100 \mathrm{hPa}$ as the average over $5^{\circ} \mathrm{S}-15^{\circ} \mathrm{N}, 90^{\circ} \mathrm{E}-180^{\circ}$.

relation to the pressure level used to define the QBO phases together with differences in tropical zonal wind at $70 \mathrm{hPa}$ (light blue), tropical temperature (red), and cloud area fraction over the tropical western Pacific (dark blue) at $100 \mathrm{hPa}$, the region in which the QBO signature on cloud area fraction is statistically significant (Fig. 7a). As expected, it shows a linear relationship between zonal mean tropical zonal wind at $70 \mathrm{hPa}$ and QBO temperature and deep convection anomalies at the tropical UTLS. This supports the mechanism proposed by Giorgetta et al. (1999) to explain the QBO modulation of convection through the QBO changes induced in the tropical UTLS temperature. Furthermore, it evidences a linear relationship between the QBO signature in the stratospheric polar temperature and both the QBO wind at $70 \mathrm{hPa}$ and the QBO temperature in the tropical UTLS. Accordingly, the QBO modulation of the southern winter stratospheric polar vortex is stronger for QBO phases defined between 60 and $80 \mathrm{hPa}$ and vanishes for QBO phases defined at around $25-30 \mathrm{hPa}$. This result supports the fact that, in this model simulation, the QBO modulation of convection is a main mechanism by which the QBO influences the stratospheric polar vortex in the southern winter hemisphere.

Previous studies have shown that, unlike in the Northern Hemisphere, the QBO impact in the southern extratropical stratosphere remains confined to midlatitudes throughout the winter (Baldwin and Dunkerton 1998; Anstey and Shepherd 2014) due to a stronger polar vortex that inhibits the upward propagation of planetary waves. This is consistent with our results showing that the QBO modulation of the wind reaches its maximum at latitudes around $50^{\circ} \mathrm{S}$ and vanishes at around $65^{\circ} \mathrm{S}$, giving rise to weak anomalies of the opposite sign at polar latitudes. However, no agreement is found concerning the height for the definition of the QBO phase that maximizes its impact on extratropical latitudes. Thus, Baldwin and Dunkerton (1998), using radiosonde observations, found the largest QBO signal in the extratropical southern winter for QBO phases defined at $25 \mathrm{hPa}$ while Anstey and Shepherd (2014) found it at different levels, between 30 and $10 \mathrm{hPa}$, for ERA-40 and an atmospheric general circulation model. At this point it is worth mentioning that previous studies have not been able to explain the reason why certain levels optimize the extratropical QBO signal. The apparent disagreement with our results might be due to the fact that in the model used here the QBO-polar vortex connection occurs predominantly through the modulation of tropical deep convection and thus, as has been shown, the largest extratropical response is found for QBO phases defined at levels in the lower stratosphere, which maximizes the impact on convection. Thus, differently from the Holton and Tan mechanism (Holton and Tan 1980), which explains the QBO impact on the polar vortex on the basis of the QBO modulation of the location of the subtropical critical wind line in the lower stratosphere and thereby affecting the propagation of planetary waves through the winter stratosphere, the present mechanism relies on the QBO modulation of the amplitude of wave-1 eddies propagating from the UTLS into the winter southern stratosphere through its impact on tropical deep convection. Other mechanisms based on the QBO meridional circulation (Ruzmaikin et al. 2005) or on the shift of the critical surface of the middle stratosphere (Naoe and Shibata 2010; Yamashita et al. 2011; Garfinkel et al. 2012) have been proposed to explain the QBO signature on the northern winter extratropical circulation. However, no other mechanisms besides that of Holton and Tan had been previously suggested for the QBO impact on the extratropical 
circulation of the Southern Hemisphere, which has typically received much less attention. This new pathway for the QBO-SH polar vortex connection raises the question about the possibility that more than one mechanism may contribute to the QBO extratropical signature in the southern winter hemisphere. Further research is needed to evaluate the performance and the interaction between them, which could counteract or reinforce each other.

Acknowledgments. This work was partly funded by the Spanish Ministry of Economy, Industry and Competitiveness-State Bureau of Investigation through the project CGL2016-78562-P. E. Manzini kindly acknowledges partial support by the EU Seventh Framework Program under Grant 603557 (StratoClim).

\section{REFERENCES}

Anstey, J. A., and T. G. Shepherd, 2014: High-latitude influence of the quasi-biennial oscillation. Quart. J. Roy. Meteor. Soc., 140, 1-21, https://doi.org/10.1002/qj.2132.

Baldwin, M. P., and T. J. Dunkerton, 1998: Quasi-biennial modulation of the Southern Hemisphere stratospheric polar vortex. Geophys. Res. Lett., 25, 3343-3346, https://doi.org/10.1029/ 98GL02445.

_- and Coauthors, 2001: The quasi-biennial oscillation. Rev. Geophys., 39, 179-229, https://doi.org/10.1029/1999RG000073.

Bladé, I., and D. L. Hartmann, 1995: The linear and nonlinear extratropical response of the atmosphere to transient tropical heating. J. Atmos. Sci., 52, 4448-4471, https://doi.org/10.1175/ 1520-0469(1995)052<4448:TLANER >2.0.CO;2.

Calvo, N., M. A. Giorgetta, and C. Peña-Ortiz, 2007: Sensitivity of the boreal winter circulation in the middle atmosphere to the quasi-biennial oscillation in MAECHAM5 simulations. J. Geophys. Res., 112, D10124, https://doi.org/10.1029/ 2006JD007844.

Cohen, N. Y., E. P. Gerber, and O. Bühler, 2014: What drives the Brewer-Dobson circulation?. J. Atmos. Sci., 71, 3837-3855, https://doi.org/10.1175/JAS-D-14-0021.1.

Collimore, C. C., D. W. Martin, M. H. Hitchman, A. Huesmann, and D. E. Waliser, 2003: On the relationship between the QBO and tropical deep convection. J. Climate, 16, 2552-2568, https://doi.org/10.1175/1520-0442(2003)016<2552: OTRBTQ $>2.0 . \mathrm{CO} ; 2$.

Dee, D. P., and Coauthors, 2011: The ERA-Interim reanalysis: Configuration and performance of the data assimilation system. Quart. J. Roy. Meteor. Soc., 137, 553-597, https://doi.org/ 10.1002/qj.828.

Dima, I. M., J. M. Wallace, and I. Kraucunas, 2005: Tropical zonal momentum balance in the NCEP reanalyses. J. Atmos. Sci., 62 , 2499-2513, https://doi.org/10.1175/JAS3486.1.

Garfinkel, C. I., T. A. Shaw, D. L. Hartmann, and D. W. Waugh, 2012: Does the Holton-Tan mechanism explain how the quasibiennial oscillation modulates the Arctic polar vortex? J. Atmos. Sci., 69, 1713-1733, https://doi.org/10.1175/JAS-D11-0209.1.

Gill, A. E., 1980: Some simple solutions for heat-induced tropical circulation. Quart. J. Roy. Meteor. Soc., 106, 447-462, https:// doi.org/10.1002/qj.49710644905.
Giorgetta, M. A., L. Bengtsson, and K. Arpe, 1999: An investigation of QBO signals in the East Asian and Indian monsoon in GCM experiments. Climate Dyn., 15, 435-450, https://doi.org/10.1007/s003820050292.

- and Coauthors, 2013: Climate and carbon cycle changes from 1850 to 2100 in MPI-ESM simulations for the Coupled Model Intercomparison Project phase 5. J. Adv. Model. Earth Syst., 5, 572-597, https://doi.org/10.1002/jame.20038.

Gray, W. M., J. D. Sheaffer, and J. A. Knaff, 1992: Hypothesized mechanism for stratospheric QBO influence on ENSO variability. Geophys. Res. Lett., 19, 107-110, https://doi.org/10.1029/ 91GL02950.

Hendon, H. H., and M. L. Salby, 1996: Planetary-scale circulations forced by intraseasonal variations of observed convection. J. Atmos. Sci., 53, 1751-1758, https://doi.org/10.1175/15200469(1996)053<1751:PSCFBI > 2.0.CO;2.

Hitchman, M. H., and A. S. Huesmann, 2009: Seasonal influence of the quasi-biennial oscillation on stratospheric jets and Rossby wave breaking. J. Atmos. Sci., 66, 935-946, https:// doi.org/10.1175/2008JAS2631.1.

— , and M. J. Rogal, 2010: ENSO influences on Southern Hemisphere column ozone during the winter to spring transition. J. Geophys. Res., 115, D20104, https://doi.org/10.1029/ 2009JD012844.

Holton, J. R., and H. Tan, 1980: The influence of the equatoria quasi-biennial oscillation on the global circulation at $50 \mathrm{mb}$. J. Atmos. Sci., 37, 2200-2208, https://doi.org/10.1175/15200469(1980)037<2200:TIOTEQ > 2.0.CO;2.

$\mathrm{Hu}, \mathrm{Y}$., and Q. Fu, 2009: Stratospheric warming in Southern Hemisphere high latitudes since 1979. Atmos. Chem. Phys., 9 , 4329-4340, https://doi.org/10.5194/acp-9-4329-2009.

Inatsu, M., and B. J. Hoskins, 2004: The zonal asymmetry of the Southern Hemisphere winter storm track. J. Climate, 17, 48824892, https://doi.org/10.1175/JCLI-3232.1.

James, I. N., 1988: On the forcing of planetary-scale Rossby waves by Antarctica. Quart. J. Roy. Meteor. Soc., 114, 619-637, https://doi.org/10.1002/qj.49711448105.

Jin, F., and B. J. Hoskins, 1995: The direct response to tropical heating in a baroclinic atmosphere. J. Atmos. Sci., 52, 307-319, https:// doi.org/10.1175/1520-0469(1995)052<0307:TDRTTH >2.0.CO;2.

Jungclaus, J. H., and Coauthors, 2013: Characteristics of the ocean simulations in the Max Planck Institute Ocean Model (MPIOM), the ocean component of the MPI-Earth system model. J. Adv. Model. Earth Syst., 5, 422-446, https://doi.org/ 10.1002/jame.20023.

Karoly, D. J., R. A. Plumb, and M. Ting, 1989: Examples of the horizontal propagation of quasi-stationary waves. J. Atmos. Sci., 46, 2802-2811, https://doi.org/10.1175/1520-0469(1989)046<2802 EOTHPO $>2.0 . \mathrm{CO} ; 2$.

Krismer, T. R., and M. A. Giorgetta, 2014: Wave forcing of the quasi-biennial oscillation in the Max Planck Institute Earth system model. J. Atmos. Sci., 71, 1985-2006, https://doi.org/ 10.1175/JAS-D-13-0310.1.

,-- , and M. Esch, 2013: Seasonal aspects of the quasibiennial oscillation in MPIESM and ERA40. J. Adv. Model. Earth Syst., 5, 406-421, https://doi.org/10.1002/jame.20024.

Matsuno, T., 1966: Quasi-geostrophic motions in the equatorial area. J. Meteor. Soc. Japan, 44, 25-43, https://doi.org/10.2151/ jmsj1965.44.1_25.

Matthews, A. J., and M. P. Meredith, 2004: Variability of Antarctic circumpolar transport and the southern annular mode associated with the Madden-Julian oscillation. Geophys. Res Lett., 31, L24312, https://doi.org/10.1029/2004GL021666. 
Mechoso, C., and Coauthors, 1995: The seasonal cycle over the tropical Pacific in coupled ocean-atmosphere general circulation models. Mon. Wea. Rev., 123, 2825-2838, https://doi.org/ 10.1175/1520-0493(1995)123<2825:TSCOTT>2.0.CO;2.

Naoe, H., and K. Shibata, 2010: Equatorial quasi-biennial oscillation influence on northern winter extratropical circulation. J. Geophys. Res., 115, D19102, https://doi.org/10.1029/2009JD012952.

Nishii, K., and H. Nakamura, 2004: Lower-stratospheric Rossby wave trains in the Southern Hemisphere: A case study for late winter of 1997. Quart. J. Roy. Meteor. Soc., 130, 325-345, https://doi.org/10.1256/qj.02.156.

Quintanar, A. I., and C. R. Mechoso, 1995a: Quasi-stationary waves in the Southern Hemisphere. Part I: Observational data. J. Climate, 8, 2659-2672, https://doi.org/10.1175/1520-0442(1995)008<2659: QSWITS $>2.0 . \mathrm{CO} ; 2$

, and —, 1995b: Quasi-stationary waves in the Southern Hemisphere. Part II: Generation mechanisms. J. Climate, 8, 26732690, https://doi.org/10.1175/1520-0442(1995)008<2673: QSWITS $>2.0 . \mathrm{CO} ; 2$.

Russo, M. R., and Coauthors, 2011: Representation of tropical deep convection in atmospheric models-Part 1: Meteorology and comparison with satellite observations. Atmos.
Chem. Phys., 11, 2765-2786, https://doi.org/10.5194/acp-112765-2011.

Ruzmaikin, A., J. Feynman, X. Jiang, and Y. L. Yung, 2005: Extratropical signature of the quasi-biennial oscillation. J. Geophys. Res., 110, D11111, https://doi.org/10.1029/2004JD005382.

Sardeshmukh, P. D., and B. J. Hoskins, 1988: The generation of global rotational flow by steady idealized tropical divergence. J. Atmos. Sci., 45, 1228-1251, https://doi.org/10.1175/15200469(1988)045<1228:TGOGRF>2.0.CO;2.

Schmidt, H., and Coauthors, 2013: Response of the middle atmosphere to anthropogenic and natural forcings in the CMIP5 simulations with the Max Planck Institute Earth system model. J. Adv. Model. Earth Syst., 5, 98-116, https://doi.org/ 10.1002/jame.20014.

Son, S., Y. Lim, C. Yoo, H. H. Hendon, and J. Kim, 2017: Stratospheric control of the Madden-Julian oscillation. J. Climate, 30, 1909-1922, https://doi.org/10.1175/JCLI-D-16-0620.1.

Yamashita, Y., H. Akiyoshi, and M. Takahashi, 2011: Dynamical response in the Northern Hemisphere midlatitude and high-latitude winter to the QBO simulated by CCSR/NIES CCM. J. Geophys. Res., 116, D06118, https://doi.org/10.1029/ 2010JD015016. 